\title{
Incorporation of chitosan and glass substrate for improvement in adsorption, separation, and stability of $\mathrm{TiO}_{2}$ photodegradation
}

\author{
M. N. I. Amir ${ }^{1}$ - N. M. Julkapli ${ }^{1}$ S. B. Abd Hamid ${ }^{1}$
}

Received: 2 September 2015/Revised: 27 October 2015 / Accepted: 30 November 2015/Published online: 4 January 2016

(C) Islamic Azad University (IAU) 2015

\begin{abstract}
It is demonstrated that single titanium dioxide $\left(\mathrm{TiO}_{2}\right)$ has high potential for photodegradation of pollutants. However, it is still far from becoming an effective photocatalyst system, due to issues of adsorption process, separation, as well as dissolution. Therefore, this study highlights the high adsorption capacity, simplified separation, and the promising stability of $\mathrm{TiO}_{2(\mathrm{SY})}$ (synthesized via sol-gel method) photocatalyst, fabricated using chitosan- $\mathrm{TiO}_{2(\mathrm{SY})}$ and supported by glass substrate (Cs$\mathrm{TiO}_{2(\mathrm{SY})} /$ glass substrate) photocatalysts. Chitosan (Cs), with abundant $-\mathrm{R}-\mathrm{NH}$ and $\mathrm{NH}_{2}$ groups, promotes the adsorption sites of methyl orange (MO) and $\mathrm{OH}$ groups for major attachment to $\mathrm{TiO}_{2(\mathrm{SY})}$. Meanwhile, the glass substrate increases stability and assists separation of the photocatalysts. Initially, nano- $\mathrm{TiO}_{2(\mathrm{SY})}$ has been characterized using high-resolution transmission electron microscope. Cs- $\mathrm{TiO}_{2(\mathrm{SY})}$ /glass substrate was fabricated via dip-coating. The distribution and interface between the photocatalytic components were characterized by Fourier transform infrared absorption spectroscopy, UV-Vis diffuse reflectance spectroscopy, field emission scanning electron microscopy, and energy-dispersive spectrometer. UV-Vis analysis of the multilayer photocatalyst $(2,4,6$, and 8 layers) was further carried out by the adsorption-photodegradation, with MO as model of pollutant. Seventy percent of the total removal of MO via optimized eight layers of photocatalyst was achieved within $1 \mathrm{~h}$ of UV
\end{abstract}

N. M. Julkapli

nurhidayatullaili@um.edu.my

1 Nanotechnology and Catalysis Research Centre (NANOCAT), 3rd Floor, Block A, Institute of Postgraduate Studies (IPS), University of Malaya, 50603 Kuala Lumpur, Malaysia irradiation. The adsorption photocatalyst achieved $50 \%$ with no exposure to UV light for $15 \mathrm{~min}$ of irradiation. It is concluded that suitable photocatalytic conditions and sample parameters possessing the multilayer photocatalyst of $\mathrm{Cs}-\mathrm{TiO}_{2(\mathrm{SY})}$ are beneficial toward the adsorption-photodegradation process in wastewater treatment.

Keywords Adsorption-photodegradation · Methyl orange $\cdot$ Titanium dioxide $\cdot$ Chitosan $\cdot$ Glass substrate

\section{Introduction}

One of the major sources of water contamination is the textile industry, due to its heavy usage of various synthetic and organic dyes (Liu et al. 2004; Pereira and Alves 2012). Various methods have been used to treat synthetic dyes, such as adsorption by various adsorbents, reverse osmosis, and flocculation. These methods are commonly used in wastewater treatment facilities, and among them, photocatalysis stands out due to its environmental-friendly nature, cost-effectiveness, and the lack of the production of secondary pollutants after the degradation of dyes.

Titanium dioxide $\left(\mathrm{TiO}_{2}\right)$ nanoparticles, or nano- $\mathrm{TiO}_{2}$ with one-dimensional structure, is a well-known semiconductor used as a photocatalyst, due to its chemical structure, biocompatibility, physical properties, catalytic activity, high surface area, non-toxicity, and promising electroconductivity (Fujishima 1972; Kijima 2010). However, nano- $\mathrm{TiO}_{2}$ is still far from becoming a potential candidate for photocatalyst systems. Bundling phenomenon and weak adherence due to the multiphase nature of $\mathrm{TiO}_{2}$ substrate remain a great challenge. Moreover, poor visible light absorption and rapid recombination of charge carriers limit the widespread use of $\mathrm{TiO}_{2}$. Therefore, the 
donor and acceptor molecules must reach the catalyst surface prior to recombination (Gupta et al. 2012). Nano$\mathrm{TiO}_{2}$ can be also easily suspended in water, clog filter membranes, and penetrate filter materials, which create problems to the separation process at the end of wastewater treatment.

Chitosan (Cs) is a biopolymer that is highly stable, and represents an idealized structure of adsorbent materials, due to its $\mathrm{R}-\mathrm{OH},-\mathrm{RNH}_{2}$, and $\mathrm{R}-\mathrm{NH}-\mathrm{R}$ structures (Dutta et al. 2004). It was reported that Cs effectively adsorbs synthetic dyes, metal ions, organic acids, and pesticide from various types of wastewater. Meanwhile, protonation of $\mathrm{R}-\mathrm{NH}_{2}$ or $\mathrm{R}-\mathrm{OH}$ functional groups of $\mathrm{Cs}$ in acidic medium helps form a good interface with nano-metal oxide. This shows the high potential of $\mathrm{Cs}$ as a support material for nano-metal oxide particles, resulting in its uniform distribution within the Cs matrix. Moreover, the use of Cs represents a promising and effective alternative as opposed to other traditional wastewater treatment methods, such as activated carbon adsorption, biological treatment, and flocculation (Zainal et al. 2009). However, $\mathrm{Cs}$ is soluble in acidic medium $(\mathrm{pKa}<4.6)$, which limits its application in highly concentrated $\mathrm{H}^{+}$ion solutions (Wongkupasert 2008).

The adsorption process involves two items: adsorbent and adsorbate, corresponding to the solid surface and pollutant that sticks to the solid surface, respectively. Adsorption is affected by the nature of adsorbates and adsorbents, the presence of other pollutants, temperature, and other atmospheric and experimental conditions. Moreover, other factors also control adsorption, such as particle size of the adsorbent, temperature, $\mathrm{pH}$, contact time, and concentration of pollutants (Ali 2010, 2012, 2014). This is important in the context of water treatment, as it uses low-cost adsorbent, resulting in a positive effect toward waste management. Moreover, management of lowcost adsorbents is an alternative that can prove inexpensive for commercialization. However, the management of the exhausted adsorbent is an important issue and has not been addressed completely. There is a need to develop more efficient, selective, inexpensive, and eco-friendly low-cost adsorbents to treat wastewater. Briefly, there is a demand for a module of low-cost adsorbents that are fast-acting and eco-friendly (Ali et al. 2012).

Promising fabrication methods have been proposed for efficient separation and adsorption of $\mathrm{TiO}_{2} / \mathrm{Cs}$ photocatalysts, including $\mathrm{TiO}_{2} / \mathrm{Cs}$ beads, $\mathrm{TiO}_{2} / \mathrm{Cs}$ multilayers, $\mathrm{TiO}_{2} /$ Cs composites, $\mathrm{TiO}_{2} / \mathrm{Cs}$ composite on cotton fibers, $\mathrm{TiO}_{2} /$ Cs with $\mathrm{SiO}_{2}$ support and $\mathrm{TiO}_{2} /$ Cs-activated carbon, and $\mathrm{TiO}_{2} / \mathrm{Cs}$ with $\mathrm{ZnO}$ nano-composite thin films (Jawad and Nawi 2012; Kim et al. 2005; Qian et al. 2011; Yu et al. 2014; Zhang et al. 2011; Zhu et al. 2012). One proposed method is the preparation of $\mathrm{TiO}_{2} / \mathrm{Cs}$ hybrid film onto substrate materials. In this approach, the photocatalyst can be separated from the reaction medium by just taking out the glass substrate from the solution.

This report discusses the photocatalytic activity of multilayer porous photocatalyst of $\mathrm{TiO}_{2(\mathrm{SY})}$ within Cs matrix on the glass substrate. Unlike previous studies of using single $\mathrm{TiO}_{2}$ or $\mathrm{TiO}_{2} / \mathrm{Cs}$ photocatalysts, the presence of glass substrates is expected to promote better stability and higher surface area of the photocatalyst system and to simplify separation after treating the photocatalyst using irradiation. In this photocatalyst system, each layer of Cs$\mathrm{TiO}_{2(\mathrm{SY})}$ photocatalyst was sandwiched in order to fabricate 2, 4, 6, and 8 layers. Thus, the adsorption of synthetic dye molecules, as well as the photocatalytic activities of $\mathrm{Cs}-\mathrm{TiO}_{2(\mathrm{SY})} /$ glass substrate, is expected to be more positive, mostly by bringing more dye molecules of methyl orange (MO) closer to the photocatalyst within the multilayers of the glass substrate.

\section{Materials and methods}

\section{Materials}

In the present study, commercial titanium isopropoxide (purity $97 \%$ ), $\mathrm{Ti}\left[\mathrm{OCH}\left(\mathrm{CH}_{3}\right)_{2}\right]_{4}$, was used as the titanium precursor, while acetic acid (purity $99 \%$ ), $\mathrm{CH}_{3} \mathrm{CO}_{2} \mathrm{H}$, was obtained from Sigma-Aldrich for the synthesis of $\mathrm{TiO}_{2(\mathrm{SY})}$. Commercial Cs (medium molecular weight) and sodium chloride, $\mathrm{NaCl}$, were obtained from Sigma-Aldrich and Merck, respectively, to prepare $\mathrm{Cs}-\mathrm{TiO}_{2(\mathrm{SY})}$ photocatalyst. MO was purchased from Sigma-Aldrich and used as the model pollutant to measure photocatalytic activity. Deionized water was used for preparing all standard solutions.

\section{Fabrication of $\mathrm{Cs}-\mathrm{TiO}_{2(\mathrm{SY})} /$ glass substrate photocatalyst}

The fabrication of $\mathrm{Cs}-\mathrm{TiO}_{2(\mathrm{SY})} /$ glass substrate began with the preparation of a Cs- $\mathrm{TiO}_{2(\mathrm{SY})}$ photocatalyst solution. Cs flake $(0.25 \mathrm{~g})$ was dissolved in a premixed solution of $\mathrm{CH}_{3} \mathrm{COOH}(30 \mathrm{ml} ; 0.1 \mathrm{M})$ and sodium chloride $(\mathrm{NaCl})$ $(4 \mathrm{ml} ; 0.2 \mathrm{M})$. The viscous solution was stirred continuously for $12 \mathrm{~h}$ before $\mathrm{TiO}_{2(\mathrm{SY})}$ powder $(0.25 \mathrm{~g})$ was added. Subsequently, $\mathrm{CH}_{3} \mathrm{COOH}(5 \mathrm{ml} ; 0.1 \mathrm{M})$ was added again, and stirring was continued for $24 \mathrm{~h}$. Then, glass substrates $(25 \times 75 \times 2 \mathrm{~mm})$ were dipped in the $\mathrm{Cs}-\mathrm{TiO}_{2(\mathrm{SY})}$ photocatalyst viscous solution with uniform immersion and dried at $100{ }^{\circ} \mathrm{C}$ for $4 \mathrm{~h}$ alternately after each dipping process. The process was repeated to deposit $2,4,6$, and 8 layers of $\mathrm{Cs}-\mathrm{TiO}_{2(\mathrm{SY})}$ photocatalyst onto the glass substrate. 


\section{Characterization of $\mathrm{TiO}_{2(\mathrm{SY})}$ and $\mathrm{Cs}-\mathrm{TiO}_{2(\mathrm{SY})} /$ glass substrate photocatalyst}

The prepared $\mathrm{TiO}_{2(\mathrm{SY})}$ was characterized using a JEM$2100 \mathrm{~F}$ high-resolution transmission electron microscope (HR-TEM) at an accelerating voltage of $200 \mathrm{kV}$. The prepared $\mathrm{TiO}_{2(\mathrm{SY})}$ and $\mathrm{Cs}$ on the glass substrate, namely Cs- $\mathrm{TiO}_{2(\mathrm{SY})} /$ glass substrate, were characterized using Fourier transform infrared absorption spectroscopy (FTIR), UV-Vis diffuse reflectance spectroscopy (UVDR), and field emission scanning electron microscopy + energy-dispersive spectrometer (FESE$\mathrm{M}+$ EDS) analysis at $4 \mathrm{~cm}^{-1}$ with 16 scans, in the wavelength range $400-4000 \mathrm{~cm}^{-1}$ of FTIR spectrum (Perkin-Elmer 100 spectrophotometer), providing molecular absorption and transmission (specific frequency of energy). FESEM analysis was done using scanning electron microscope (JSM-7500F, JEOL) at an acceleration voltage of $5 \mathrm{kV}$. The elemental analysis of the Cs$\mathrm{TiO}_{2(\mathrm{SY})} /$ glass substrate of photocatalyst samples was conducted using EDS, with the energy of the beam in the range of 10-20 keV. The band gap energy analysis was conducted using UV-DR spectrophotometer model UV3101PC Shimadzu, with wavelengths ranging from 200 to $800 \mathrm{~nm}$.

\section{Photocatalytic activity of $\mathrm{Cs}-\mathrm{TiO}_{2(\mathrm{SY})} /$ glass substrate}

A UV light lamp ( $6 \mathrm{~W}, \lambda=365 \mathrm{~nm}$ ) was used to initiate adsorption-photodegradation activity from prepared photocatalyst within a 150-ml Pyrex reactor containing $10 \mathrm{ppm} \mathrm{MO}$. For the first $15 \mathrm{~min}$, the sample was allowed to adsorb on the surface of the photocatalyst before being irradiated with a UV light lamp for the next hour. A sample of $5 \mathrm{ml}$ was removed (including previous $15 \mathrm{~min}$ ) at 10, 20, 30, 40, 50, and $60 \mathrm{~min}$ (Bagheri et al. 2015). The photocatalytic activity of $\mathrm{Cs}-\mathrm{TiO}_{2(\mathrm{SY})} /$ glass substrate systems was usually evaluated by measuring the time dependence of the concentration loss based on adsorbed and degraded MO compound. MO is used due to its high stability and common UV-Vis spectroscopic profile under a variety of conditions, which encompasses the initial MO concentration, $\mathrm{pH}$, photocatalyst dosage, and solar irradiation intensity. Furthermore, the absorbance data of the MO samples were obtained from the optical spectra recorded on UV-Vis analysis using model of UV-3101PC Shimadzu, with wavelengths ranging from 200 to $800 \mathrm{~nm}$. After that, the multilayer photocatalyst was used with exactly similar photocatalytic activity from previous conditions as an evaluation parameter.

The percentage of adsorption-photodegradation was calculated using the following formula:
$\% \mathrm{~A}-\mathrm{P}=\frac{C_{\mathrm{o}}-C_{t}}{C_{\mathrm{o}}} \times 100 \%$

where $\% \mathrm{~A}-\mathrm{P}=$ percentage of adsorption and photodegradation; $C_{\mathrm{o}}=$ initial concentration of sample before irradiation under UV light; and $C_{t}=$ concentration of sample after irradiation under UV light $(t$, minutes).

\section{Results and discussion}

\section{Characterization of the synthesized $\mathrm{TiO}_{2(\mathrm{SY})}$ photocatalyst}

For HR-TEM analysis, the interaction of electrons with the specimen provides morphologic and compositional information of nano-materials. The prepared $\mathrm{TiO}_{2(\mathrm{SY})}$ photocatalyst was characterized by HR-TEM analysis. The interaction of electrons with the specimen provides morphologic and compositional information of nano- $\mathrm{TiO}_{2(\mathrm{SY})}$. The particle size and shape of the nano-sample are determined from the HR-TEM images shown in Fig. 1. The analysis is conducted based on the results reported in Fig. 2 and Table 1.

Figure 1 shows the HR-TEM images of the $\mathrm{TiO}_{2(\mathrm{SY})}$ sample obtained after calcination at $500{ }^{\circ} \mathrm{C}$. Generally, a homogenous dispersion and uniform particle feature, with particle sizes of $5-30 \mathrm{~nm}$ for $\mathrm{TiO}_{2(\mathrm{SY})}$, are shown. It has been demonstrated that almost $90 \%$ of the $\mathrm{TiO}_{2(\mathrm{SY})}$ is 10-20 nm. Meanwhile, another $10 \%$ of the $\mathrm{TiO}_{2(\mathrm{SY})}$ has been categorized to be less than $5 \mathrm{~nm}$ or more than $25 \mathrm{~nm}$.

Generally, 20 particles of $\mathrm{TiO}_{2(\mathrm{SY})}$ had an average particle size of $\sim 13.3 \mathrm{~nm}$ at a standard deviation of $7.2 \mathrm{~nm}$, as depicted in Fig. 2 and Table 1. This result has been confirmed that $\mathrm{TiO}_{2(\mathrm{SY})}$ was prepared via sol-gel method from the $\mathrm{Ti}\left[\mathrm{OCH}\left(\mathrm{CH}_{3}\right)_{2}\right]_{4}$ precursor $\left(\mathrm{TiO}_{2(\mathrm{SY})}\right)$ which has an anatase phase. This implies that the repartition in size is quite large, i.e., $14 \%$ of extension over the average value.

\section{Characterization of the synthesized Cs- $\mathrm{TiO}_{2(\mathrm{SY})} /$ glass substrate photocatalysts}

The $\mathrm{Cs}-\mathrm{TiO}_{2(\mathrm{SY})} /$ glass substrate photocatalysts are characterized by FTIR, UV-DR, FESEM, and EDS. The FTIR spectrum provides the molecular absorption and transmission (specific frequency of energy), which is useful for analyzing the multilayer photocatalyst of $\mathrm{Cs}-\mathrm{TiO}_{2(\mathrm{SY})} /-$ glass functional groups, while others are attached to the molecule's functional group, linking the photocatalyst with it. Characterization of FTIR spectra for formation of Cs$\mathrm{TiO}_{2(\mathrm{SY})}$ /glass substrate multilayer photocatalyst together with single $\mathrm{TiO}_{2(\mathrm{SY})}$ is shown in Fig. 3. Absorption bands at 1640 and $3600-3300 \mathrm{~cm}^{-1}$ are attributed to amide (R- 


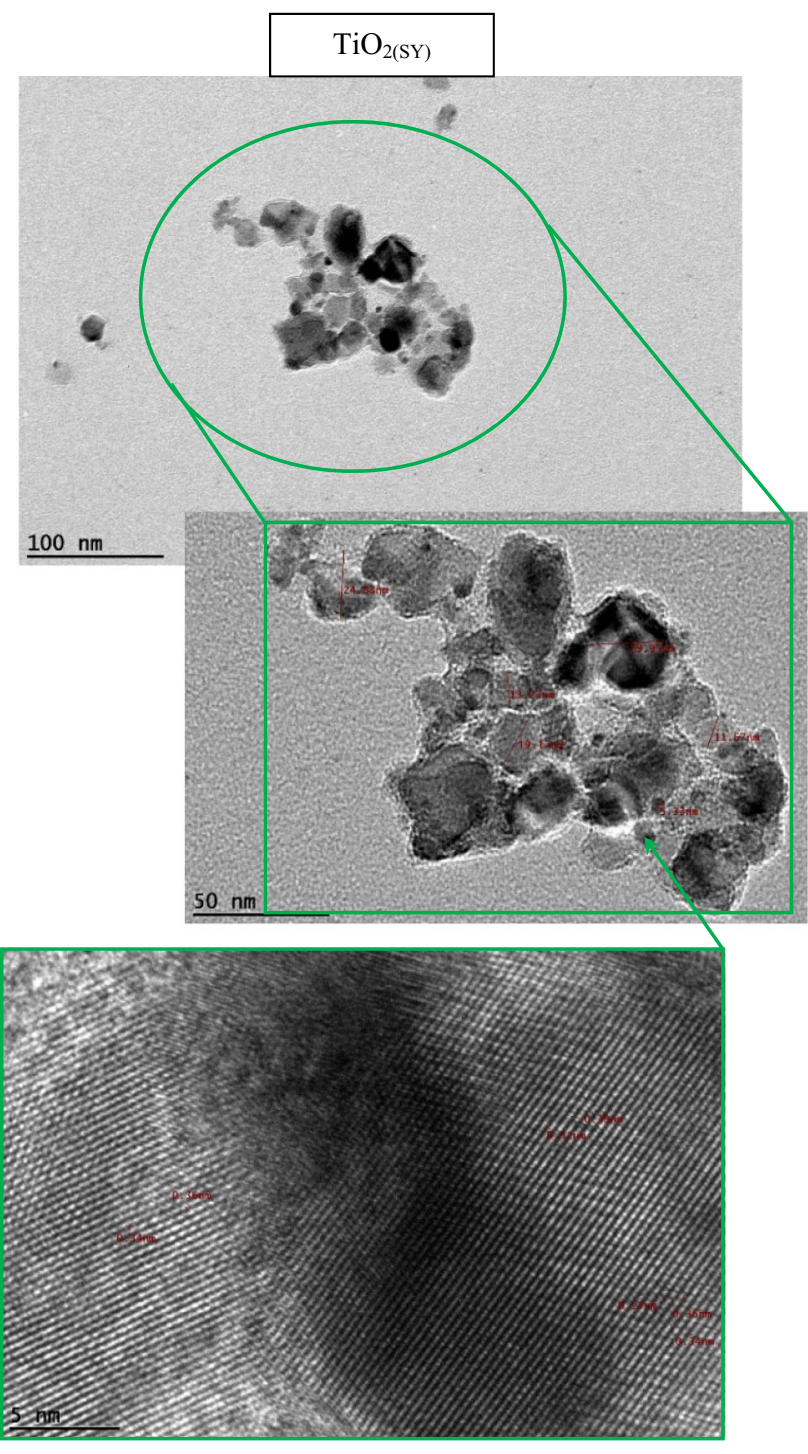

Fig. 1 HR-TEM micrographs of $\mathrm{TiO}_{2(\mathrm{SY})}$ photocatalyst with magnification of $\times 60,000$

$\mathrm{NH}-\mathrm{R})$ and hydroxyl $(-\mathrm{OH})$, together with amine $\left(-\mathrm{NH}_{2}\right)$ functional groups of $\mathrm{Cs}$ macromolecules for $\mathrm{Cs}-$ $\mathrm{TiO}_{2(\mathrm{SY})} /$ glass substrate. These series of functional groups on Cs chains serve as coordination and reaction sites for the adsorption of transition metals and organic species (Yao et al. 2011). The presence around the specific band at $700 \mathrm{~cm}^{-1}$ is assigned for Ti-O and Ti-O-Ti bonding of $\mathrm{TiO}_{2(\mathrm{SY})}$ (Saleh and Gupta 2012a). However, there is an intriguing anomaly on the adsorption band of FTIR spectrum in the context of $\mathrm{Cs}-\mathrm{TiO}_{2(\mathrm{SY})}$ photocatalyst, which is due to the rough absorption bands of $-\mathrm{OH}$ group at 1400 , 1535,3420 , and $3745 \mathrm{~cm}^{-1}$, while the strong band at $3600-3300 \mathrm{~cm}^{-1}$ is attributed to characteristic of a surface $\mathrm{TiO}_{2}-\mathrm{OH}$ group. On the other hand, the absorption bands at $1280-1070 \mathrm{~cm}^{-1}$ were attributed to the silicon-oxygen bonds $(\mathrm{Si}-\mathrm{O})$ functional groups. The significant increment

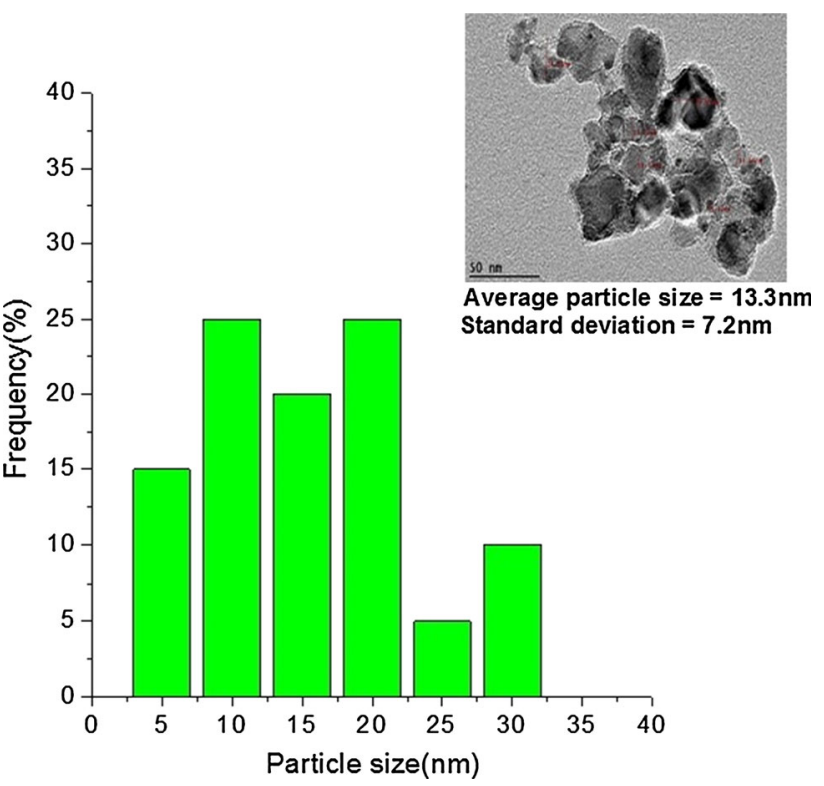

Fig. $2 \mathrm{PSD}$ of $\mathrm{TiO}_{2(\mathrm{SY})}$ (green) with inset at $\times 60,000$ magnification

Table 1 Particle size and shape of $\mathrm{TiO}_{2(\mathrm{SY})}$

\begin{tabular}{lllll}
\hline Samples & Size $(\mathrm{nm})$ & Shape & & \\
\cline { 3 - 5 } & & Cubic & Semi-sphere & Needle \\
\hline Synthesis via sol-gel method & & & \\
$\mathrm{TiO}_{2(\mathrm{SY})}$ & 13.3 & $\mathrm{~A}$ & N/A & N/A \\
\hline
\end{tabular}

N/A not available, $A$ available

in the bands was centered on $450-950 \mathrm{~cm}^{-1}$, recorded for multilayer photocatalyst of $\mathrm{Cs}-\mathrm{TiO}_{2(\mathrm{SY})} /$ glass substrate. The band increment became more significant as the number of layers from 2 to 8 . It is worth noting that the FTIR spectra of the synthesized $\mathrm{Cs}-\mathrm{TiO}_{2(\mathrm{SY})}$ photocatalyst showed more bands with higher intensities compared with the precursor $\mathrm{TiO}_{2(\mathrm{SY})}$ and Cs. It is indicated that the FTIR detection is enhanced when the photocatalysts consisted of both $\mathrm{TiO}_{2(\mathrm{SY})}$ and Cs. Moreover, the apparent existence of $\mathrm{NH}_{2}, \mathrm{R}-\mathrm{NH}$, and $\mathrm{OH}$ functional groups, together with $\mathrm{TiO}_{2(\mathrm{SY})}$ metal oxide, should help confirm the effective removal of MO via the adsorption-photodegradation process. This can be explained by the adsorption of $\mathrm{MO}$ moleculars onto the $\mathrm{Cs}$ structure. Cs forms chelation between $\mathrm{NH}_{2}-\mathrm{MO}$ and molecules- $\mathrm{NH}_{2}$ within its long chain structure. It was previously proven that these functional groups act as adsorption sites and consequently increase the adsorption capacity of photocatalyst system (Kyzas and Bikiaris 2015).

UV-DR analysis was conducted to determine the band gap energy and absorption edge of the prepared Cs$\mathrm{TiO}_{2}$ /glass substrate multilayer photocatalyst. Figure 4 presents the UV-DR spectra pattern for multilayer 


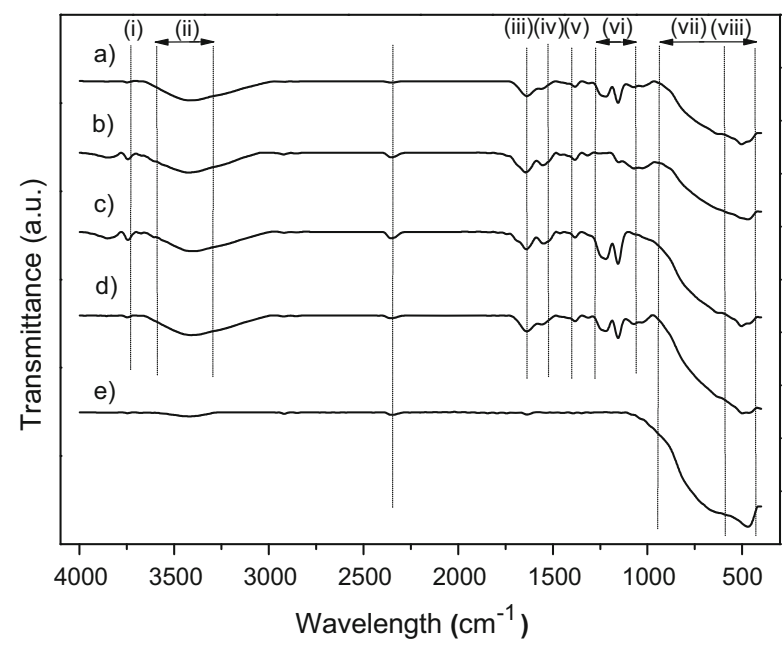

\begin{tabular}{|c|c|c|}
\hline \hline \multicolumn{1}{|c|}{ Symbol } & Wavelength $\mathbf{( c m}^{-1} \mathbf{)}$ & Assignment \\
\hline \hline (i) & 3745 & $-\mathrm{OH}$ group \\
\hline (ii) & 3600 to 3300 & $\begin{array}{c}-\mathrm{OH} \text { overlapping together with - } \\
\mathrm{NH}_{2} \text { of Cs groups and }-\mathrm{OH} \text { group } \\
\text { to } \mathrm{TiO}_{2} \text { element attachment }\end{array}$ \\
\hline (iii) & 1640 & $\mathrm{R}-\mathrm{NH}-\mathrm{R}$ bending \\
\hline (iv) and (v) & 1535 and 1400 & $-\mathrm{OH}$ deformation \\
\hline (vi) & 1280 to 1070 & Bridge of Si-O \\
\hline (vii) & 450 to 950 & $\begin{array}{c}\mathrm{TiO}_{2} \text { with shape of layers } \\
\text { formation between Cs-TiO } \\
\text { the glass substrate }\end{array}$ \\
\hline (viii) & 700 & TiO $_{2}$ wagging \\
\hline \hline
\end{tabular}

Fig. 3 FTIR spectra of $\mathrm{Cs}-\mathrm{TiO}_{2(\mathrm{SY})}$ /glass substrate multilayers photocatalyst which are $a 2$ layers, $b 4$ layers, $c 6$ layers, and $d 8$ layers together with $e \mathrm{TiO}_{2(\mathrm{SY})}$

photocatalyst of $\mathrm{Cs}-\mathrm{TiO}_{2(\mathrm{SY})}$ /glass substrate. The band gap energy increased with layers from 2 to 4 . It has demonstrated an increment in the band gap energy from 2.43 to $2.70 \mathrm{eV}$. The band gap decreases gradually from 4 layers until 8 layers at up to $0.96 \mathrm{eV}$. It can be anticipated that the

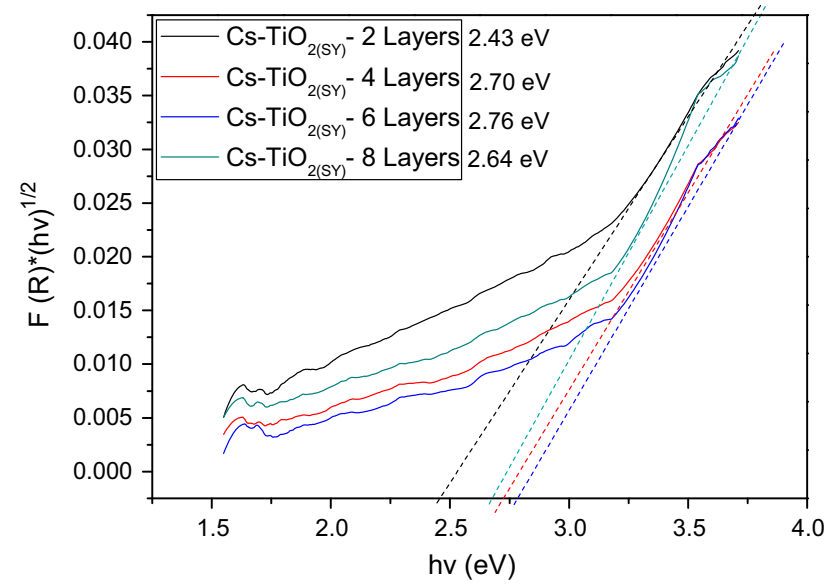

Fig. 4 UV-DR spectra of $\mathrm{Cs}-\mathrm{TiO}_{2(\mathrm{SY})} /$ glass substrate multilayers photocatalyst which are 2, 4, 6, and 8 layers band gap of the 8-layer photocatalyst for $\mathrm{Cs}-\mathrm{TiO}_{2(\mathrm{SY})} /$ glass substrate is $2.64 \mathrm{eV}$. It was also demonstrated that the 8-layer photocatalyst of $\mathrm{Cs}-\mathrm{TiO}_{2} /$ glass substrate was prepared by successive deposition cycles to guarantee the excellent distribution of nano- $\mathrm{TiO}_{2(\mathrm{SY})}$. This, in turn, renders the $\mathrm{Cs}-\mathrm{TiO}_{2(\mathrm{SY})} /$ glass substrate multilayer photocatalyst system, with the capability of absorbing photonic energy with wavelengths under $391 \mathrm{~nm}$ in the reflectance analysis.

Therefore, in this case, the coupled multilayer photocatalyst of $\mathrm{Cs}-\mathrm{TiO}_{2(\mathrm{SY})} /$ glass substrate is expected to give higher adsorption-photodegradation efficiency than single $\mathrm{TiO}_{2}$ in total removal of MO.

The morphology of $\mathrm{Cs}-\mathrm{TiO}_{2} /$ glass substrate multilayer photocatalyst with distribution, surface structure, and homogeneity of nano- $\mathrm{TiO}_{2(\mathrm{SY})}$ within $\mathrm{Cs}$ matrix was analyzed using the FESEM. Figure 5 illustrates the FESEM micrographs of $\mathrm{Cs}-\mathrm{TiO}_{2(\mathrm{SY})} /$ glass substrate multilayer photocatalyst. These series of dipping samples were prepared for $\mathrm{Cs}-\mathrm{TiO}_{2(\mathrm{SY})}$ photocatalyst. The FESEM micrographs of $\mathrm{Cs}-\mathrm{TiO}_{2(\mathrm{SY})} /$ glass substrate with similar weight ratio of 2:2 (0.25 g of Cs:0.25 g of $\left.\mathrm{TiO}_{2}\right)$ were shown for $\mathrm{TiO}_{2(\mathrm{SY})}$. These series of dipping photocatalyst were prepared for $\mathrm{Cs}-\mathrm{TiO}_{2(\mathrm{SY})}$ photocatalyst. Generally, all multilayer photocatalysts demonstrated a macroreticular structure with a spherical primary nano- $\mathrm{TiO}_{2(\mathrm{SY})}$ with a particle size of $10-30 \mathrm{~nm}$. The photocatalyst of Cs$\mathrm{TiO}_{2(\mathrm{SY})} /$ glass substrate was more homogeneous and dispersed uniformly until the number of layers became 8 .

EDS is an analytical technique used for elemental analysis or chemical characterization. Overall, Table 2 shows the EDS analysis of element weight percent for all the elements present in the $\mathrm{Cs}-\mathrm{TiO}_{2(\mathrm{SY})} /$ glass substrate, resulting in a total of $100 \mathrm{wt} \%$. The analysis indicates the coexistence of $\mathrm{Si}, \mathrm{C}, \mathrm{O}, \mathrm{Ti}$, and $\mathrm{N}$ elements. It has confirms that the photocatalysis with number of layers of 2 and 8 Cs $-\mathrm{TiO}_{2(\mathrm{SY})} /$ glass substrate obtained the weight ratio of $\mathrm{O}$ to $\mathrm{TiO}_{2}$ is 6:1. The multilayers proved that the one with the lesser multilayers tends to have less amounts of $\mathrm{TiO}_{2}$ and Cs bonds compared to those with higher number of layers. Furthermore, the photocatalysts, from 2 to 8 layers of Cs$\mathrm{TiO}_{2(\mathrm{SY})}$ /glass substrate, demonstrated an increment in the amount of $\mathrm{O}$ and $\mathrm{Ti}$ elements. Besides that, $\mathrm{Si}$ has been reduced for $\mathrm{Cs}-\mathrm{TiO}_{2(\mathrm{SY})} /$ glass substrate from 2 to 8 layers.

This suggests that $\mathrm{TiO}_{2}$ was successfully distributed within the Cs matrix via coordinate covalent bonding. Bond formation are possible between the Cs via metal ions. The formation would take place between $-\mathrm{OH}$ group (obtain from Cs) and $\mathrm{Ti}^{4+}$ (obtain from $\mathrm{TiO}_{2}$ ). Furthermore the $-\mathrm{NH}_{2}$ group of Cs produces hydrogels that can be used for attachment to a glass substrate. In the meantime, the $\mathrm{NH}_{2}$ group of $\mathrm{Cs}$ produces hydrogels that can be used for attachment to a glass substrate. Moreover, $\mathrm{TiO}_{2(\mathrm{SY})}$ was 

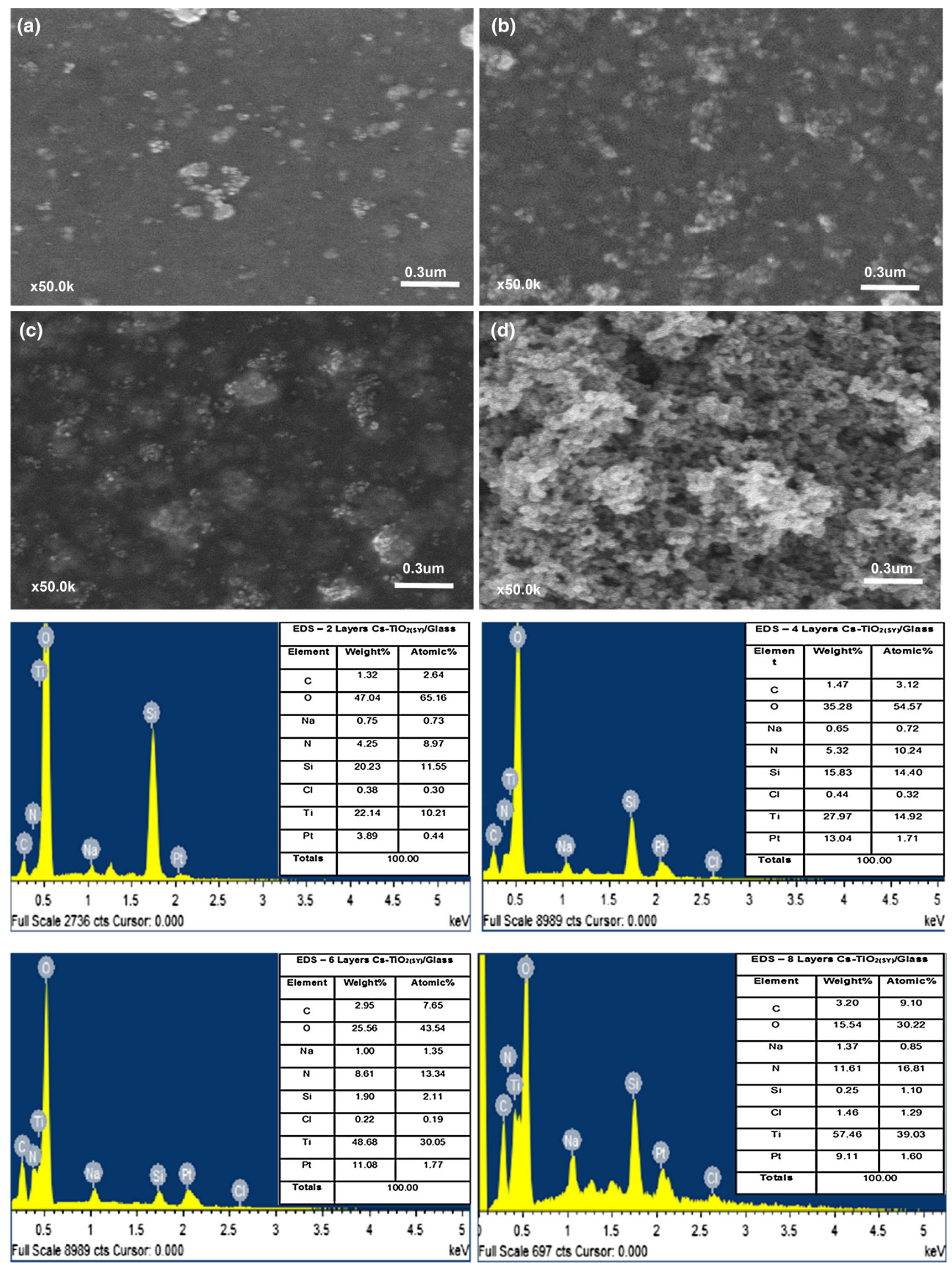

Springer 
4Fig. 5 FESEM micrographs of multilayer photocatalyst a 2 layers, b 4 layers, c 6 layers, d 8 layers of $\mathrm{Cs}-\mathrm{TiO}_{2(\mathrm{SY})} /$ glass substrate with magnification of $\times 50,000$ include with EDS figures and tables for that samples, respectively

Table 2 EDS of Cs- $\mathrm{TiO}_{2(\mathrm{SY})} /$ glass substrate multilayer photocatalyst that is relative to layer formations

\begin{tabular}{llllll}
\hline Samples & \multicolumn{5}{l}{ Elements' weight percentage $(\%)$} \\
\cline { 2 - 6 } & $\mathrm{C}$ & $\mathrm{O}$ & $\mathrm{N}$ & $\mathrm{Si}$ & $\mathrm{Ti}$ \\
\hline $\mathrm{Cs}^{2}-\mathrm{TiO}_{2(\mathrm{SY})}$ /glass substrate & & & \\
2 layers & 1.32 & 47.04 & 4.25 & 20.23 & 22.14 \\
4 layers & 1.47 & 35.28 & 5.32 & 15.83 & 27.97 \\
6 layers & 2.95 & 25.56 & 8.61 & 1.90 & 48.68 \\
8 layers & 3.20 & 15.54 & 11.61 & 0.25 & 57.46 \\
\hline
\end{tabular}

completely dispersed as the nanoparticles were submerged into the coated layers. Further observation leads us to conclude that the surface nano- $\mathrm{TiO}_{2(\mathrm{SY})}$ was directly proportional to the number of layers. This would allow the Cs matrix to function as an adsorption medium, while the surface of $\mathrm{TiO}_{2(\mathrm{SY})}$ acts as a photoelectron center via promotion and excitation with light illumination of a suitable wavelength. Hence, this confirmed that the photodegradation process plays a major role in 6-8 layers for $\mathrm{Cs}-\mathrm{TiO}_{2(\mathrm{SY})} /$ glass substrate, due to the abundance of $\mathrm{TiO}_{2(\mathrm{SY})}$, whereas the removal of MO would predominantly be attributed to the adsorption process by Cs.

\section{Photocatalytic activity of MO adsorption- photodegradation}

The UV-Vis analysis was carried out to quantitatively analyze the photocatalytic activities of $\mathrm{Cs}-\mathrm{TiO}_{2(\mathrm{SY})} /$ glass substrate multilayer photocatalyst by relying on the MO photodegradation and including adsorption process. The adsorption-photodegradation activity of $\mathrm{Cs}-\mathrm{TiO}_{2(\mathrm{SY})} / \mathrm{glass}$ substrate toward $10 \mathrm{ppm}$ of $\mathrm{MO}$ as a model of pollutant compound with layers of 2, 4, 6, and 8 is shown in Fig. 6. Approximately $50 \%$ of the MO was adsorbed at initial stage (15-min adsorption in dark condition) and followed by the photodegradation (60-min degradation with UV light irradiation). The photocatalytic activities of Cs$\mathrm{TiO}_{2(\mathrm{SY})} /$ glass substrate were analyzed based on the percentage of adsorption-photodegradation and final concentrations of MO. Firstly, photocatalyst with 2 layers showed the lowest MO adsorption about $30 \%$. With that, the remainder of $\mathrm{MO}$ concentration at $15 \mathrm{~min}$ of adsorption process was recorded to be $7.0 \mathrm{ppm}$. As far as photodegradation is concerned, 2-layer photocatalyst was

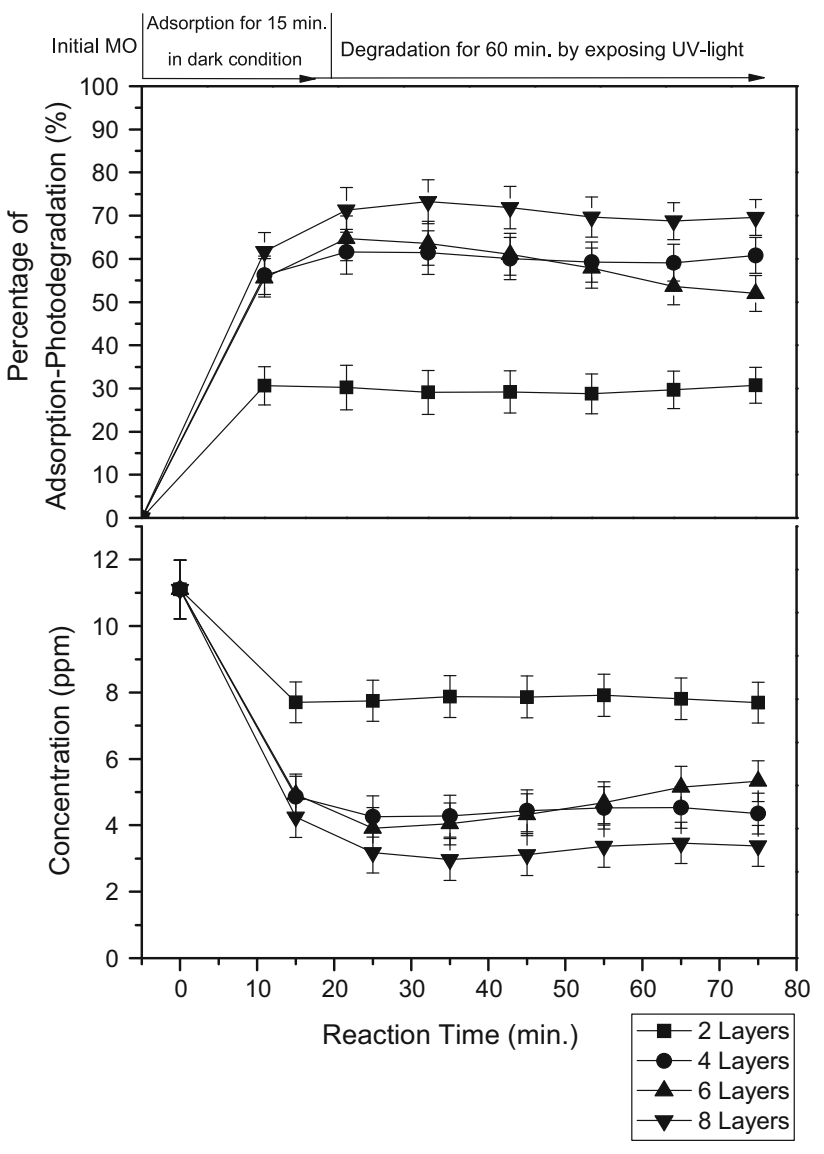

Fig. 6 Adsorption and photodegradation of $\mathrm{Cs}-\mathrm{TiO}_{2(\mathrm{SY})} /$ glass substrate multilayer photocatalyst

recorded to be $30 \%$ at $6.4 \mathrm{ppm}$ of $\mathrm{MO}$ remaining. The adsorption and photodegradation processes improved as the layers increased from 4 to 8 . The 4-layer photocatalyst results in about $\sim 50 \% \mathrm{MO}$ adsorption with total removal of $5.0 \mathrm{ppm}$. The introduction of UV light resulted in an MO photodegradation of $61 \%$, at final concentrations of $4.3 \mathrm{ppm}$ of $\mathrm{MO}$ by $\mathrm{Cs}-\mathrm{TiO}_{2(\mathrm{SY})} /$ glass substrate. The MO adsorption for the photocatalyst of 6 layers was recorded to be $56 \%$, removing a total of $4.8 \mathrm{ppm}$ of MO. However, the photodegradation did not show much difference in terms of percentage and concentrations of MO.

Furthermore, the 8 layers of $\mathrm{Cs}-\mathrm{TiO}_{2(\mathrm{SY})} /$ glass substrate demonstrated the highest total removal of the MO. At the adsorption stage, $65 \%$ of MO removal with final concentrations of $4.0 \mathrm{ppm}$ for $\mathrm{Cs}-\mathrm{TiO}_{2(\mathrm{SY})} / \mathrm{glass}$ substrate is removed. Then, the photodegradation process was recorded to be $67-70 \%$ removal. Once the process of photocatalytic activity was completed, the concentration of the remaining MO was recorded to be $3.4 \mathrm{ppm}$. This can be explained by the fact that samples with more layers contain higher percentages of $\mathrm{Cs}$ as its absorbent and $\mathrm{TiO}_{2}$ as its center of photodegradation. This can be further explained by 
Table 3 List of different photocatalysts with support of carbon as adsorbent in photocatalyst system to stimulate removal toward different pollutants

\begin{tabular}{|c|c|c|c|}
\hline $\mathrm{TiO}_{2}$ photocatalyst system & Pollutants & Removal (\%) & References \\
\hline $\begin{array}{l}\text { Multiwall carbon nanotubes } \\
\text { (MWCNTs)/nano-iron oxide }\end{array}$ & Chromium & 90 & Gupta et al. (2011a) \\
\hline Alumina-coated carbon nanotubes & Lead & More than 99 & Gupta et al. (2011b) \\
\hline Multiwall carbon nanotubes (MWCNTs) $/ \mathrm{MnO}_{2}$ & Arsenic & More than 95 & Saleh et al. (2011) \\
\hline Multiwall carbon nanotubes (MWCNTs)/ZnO & Cyanide & 90 & Saleh et al. (2010) \\
\hline
\end{tabular}

adsorption occurred on the inter-H-bonds interaction between the $-\mathrm{OH}$ and $-\mathrm{NH}_{2}$ groups of $\mathrm{Cs}$, with the polar groups of $\mathrm{MO}$.

Thus, the MO removal is influenced by number of layers in photocatalyst system. The reason for MO molecular adsorption is derived from the $\mathrm{Cs}$ forms chelation between $\mathrm{NH}_{2}-\mathrm{MO}$ and molecules- $\mathrm{NH}_{2}$ within its long-chain structure. Interestingly, adsorption capability increases with increasing $\mathrm{Cs}-\mathrm{TiO}_{2(\mathrm{SY})}$ photocatalyst loading into glass substrate from 2 until 8 layers. It is evident that adsorption capability of Cs had not reached its maximum limit (Zainal et al. 2009). It can be explained that the sample with more layers contains high percentage of $\mathrm{Cs}$ as adsorbent and $\mathrm{TiO}_{2(\mathrm{SY})}$ as a center for the photodegradation. The adsorption occurred via the inter-H-bonds interaction between the $-\mathrm{OH}$ and $-\mathrm{NH}_{2}$ groups of $\mathrm{Cs}$ with the polar groups of MO. Once the MO has been introduced into the photocatalyst system, the reduction in MO would consequently occur by the photooxidation process which resulted in $\mathrm{CO}_{2}$ and $\mathrm{CO}$. Moreover, Table 3 shows several convenient interdisciplinary studies using different metal oxides with carbon as its adsorbent. It concluded that high levels of removal toward the selected pollutants is observed with different types of carbon support materials.

\section{Mechanism of MO adsorption-photodegradation}

FTIR is a useful analysis that helps identify types of functional groups of photocatalysts that are responsible for entrapping the molecules of dye, as illustrated in Fig. 7. Apparently, the presence of functional groups on adsorption site could be realized by $\mathrm{NH}_{2}, \mathrm{NH}$, and $\mathrm{OH}$ functional groups, together with $\mathrm{TiO}_{2}$ metal oxide. Series of functional groups help confirm the effective removal of $\mathrm{MO}$ throughout the adsorption-photodegradation process. The process resulted in some changes from the interaction between the photocatalyst system and the MO solution. First, the presence of $\mathrm{TiO}_{2(\mathrm{SY})}$ molecule was proven by the presence of strong absorbance bands at $498 \mathrm{~cm}^{-1}$, with a shoulder at $680 \mathrm{~cm}^{-1}$. In the absorption band at $3745 \mathrm{~cm}^{-1}$, the spectral transmittance also appears as sharper bands for $\mathrm{Cs}-\mathrm{TiO}_{2(\mathrm{SY})}$ photocatalyst, indicating that $-\mathrm{OH}$ groups of $\mathrm{Cs}$ have been attached to $\mathrm{TiO}_{2}$ network

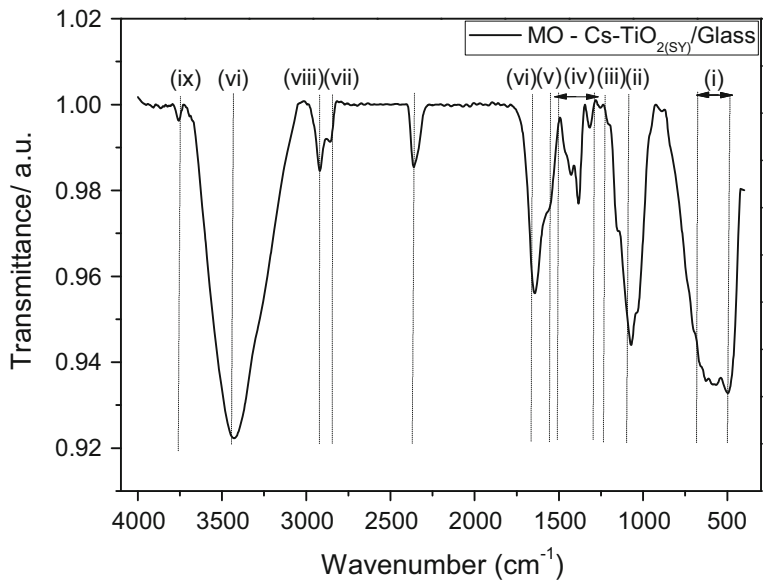

\begin{tabular}{|c|c|c|}
\hline Symbol & Wavelength $\left(\mathrm{cm}^{-1}\right)$ & Assignment \\
\hline (i) & 498 to 680 & $\begin{array}{c}\mathrm{TiO}_{2} \text { with shape of } 8 \text { layers } \\
\text { formation with Cs }\end{array}$ \\
\hline (ii) & 1081 & $\mathrm{~S}=\mathrm{O}$ vibration \\
\hline (iii) & 1315 & $-\mathrm{C}=\mathrm{N}$ stretching of $\mathrm{MO}$ \\
\hline (iv) & 1490 to 1280 & $\begin{array}{l}\text { Stretching bands of }-\mathrm{NH}_{2} \text { from } \\
\text { Cs to be attached with }-\mathrm{CH}_{3} \text { from } \\
\text { MO }\end{array}$ \\
\hline (v) & 1535 & $\mathrm{C}-\mathrm{N}$ and $\mathrm{C}-\mathrm{N}-\mathrm{H}$ mode of $\mathrm{Cs}$ \\
\hline (vi) & 1660 & $\begin{array}{l}\mathrm{N}-\mathrm{H} \text { bending vibration in }-\mathrm{NH}_{2} \\
\text { group of Cs }\end{array}$ \\
\hline (vi) & 3420 & $-\mathrm{OH}$ groups of $\mathrm{Cs}$ \\
\hline (vii) & 2850 & $\begin{array}{l}\mathrm{OH} \text { bands of surface } \mathrm{TiO}_{2}-\mathrm{OH} \\
\text { functional groups }\end{array}$ \\
\hline (viii) & 2920 & $-\mathrm{C}-\mathrm{H}$ stretching \\
\hline (ix) & 3745 & $\begin{array}{l}\text { Indicating that }-\mathrm{OH} \text { groups of } \mathrm{Cs} \\
\text { to be attached with } \mathrm{TiO}_{2} \text { network }\end{array}$ \\
\hline
\end{tabular}

Fig. 7 FTIR spectra of MO with 8-layer photocatalyst of Cs$\mathrm{TiO}_{2(\mathrm{SY})} /$ glass substrate after photocatalytic activities

(Fajriati et al. 2014). Furthermore, the adsorption bands of Cs were measured at 3420 and $1660 \mathrm{~cm}^{-1}$, which was assigned to its $-\mathrm{OH}$ (mostly adsorption toward $\mathrm{TiO}_{2}$ ) and $\mathrm{NH}_{2}$ (mostly adsorption toward MO) functional groups. Moreover, the multilayer photocatalyst on the Cs$\mathrm{TiO}_{2(\mathrm{SY})} /$ glass substrate is related to the enhanced permeated pure water via the polarity $-\mathrm{OH}$ and can interact with water molecules through van der Waals force and $\mathrm{H}$-bond (Saleh and Gupta 2012b). Furthermore, Cs mode can be confirmed via the band at $1535 \mathrm{~cm}^{-1}$, which help identify the functional groups of $-\mathrm{C}-\mathrm{N}$ and $\mathrm{C}-\mathrm{N}-\mathrm{H}$, while bands of $-\mathrm{NH}$ and $\mathrm{C}=\mathrm{O}$ have also been observed at $1660 \mathrm{~cm}^{-1}$ (Kavitha et al. 2013). 
The effectiveness of the photocatalytic reaction hinges more on the adsorption rather than on photodegradation process, due to the present amount of MO molecules after the completion of the photocatalytic reaction. There are some new spectrum bands (MO functional groups) appearing, which is obvious post-analysis. Moreover, MO molecules are detectable after absorption by Cs molecules. The band at $1660 \mathrm{~cm}^{-1}$ was clearly weakened after the photodegradation process, which might be due to $-\mathrm{NH}_{2}$ groups in its role of absorbing MO. The range of bending attributed to the $-\mathrm{C}=\mathrm{N}$ stretching was observed at $1315 \mathrm{~cm}^{-1}$, while $\mathrm{C}=\mathrm{C}$ stretching at $1660 \mathrm{~cm}^{-1}$ was observed between the binding of Cs and MO. Most of adsorption functional groups of $\mathrm{Cs}$ have been identified from 1490 to $1280 \mathrm{~cm}^{-1}$, attributed to the existence of protonated $-\mathrm{NH}_{2}$ groups in the Cs structure, forming $\mathrm{H}$-bonds with the $-\mathrm{CH}_{3}$ site from the MO molecule. In a nutshell, most MO molecules can be obtained from the adsorption process via Cs. The interaction of MO molecules with the photocatalyst could be demonstrated at $1380 \mathrm{~cm}^{-1}$, which shows the stretching of $\mathrm{C}-\mathrm{C}$ and $\mathrm{N}=\mathrm{N}$ vibrations, respectively. The aromatic $-\mathrm{C}-\mathrm{H}$ stretching band at $2920 \mathrm{~cm}^{-1}$ indicates the presence of MO molecules within the photocatalyst. Furthermore, the spectra were recorded in the form of a strong increase in absorbance level below $1081 \mathrm{~cm}^{-1}$, representing the stretching of $-\mathrm{S}=\mathrm{O}$ functional groups. Confirmation with the characteristics of $\mathrm{MO}$ molecules was at $1081 \mathrm{~cm}^{-1}-\mathrm{S}=\mathrm{O}$ stretching vibrations, $2920 \mathrm{~cm}^{-1}-\mathrm{CH}$ stretching, and $1315 \mathrm{~cm}^{-1}-\mathrm{C}=\mathrm{N}$ stretching (Nandini and Vishalakshi 2012). The band around $2360 \mathrm{~cm}^{-1}$ (the line without label) was not characteristic of $\mathrm{Cs}-\mathrm{TiO}_{2(\mathrm{SY})}$ photocatalyst, or even $\mathrm{MO}$, but was due to $\mathrm{CO}_{2}$, which might affect calculations.

\section{Conclusion}

In this study, the photocatalytic activity for the total removal of MO solution was determined using multilayer photocatalyst of $\mathrm{Cs}-\mathrm{TiO}_{2(\mathrm{SY})} /$ glass substrate. The HR-TEM analysis of $\mathrm{TiO}_{2(\mathrm{SY})}$ showed an average homogenous dispersion and uniform particulate features with average particle sizes of $13.3 \mathrm{~nm}$. The Cs$\mathrm{TiO}_{2(\mathrm{SY})} /$ glass substrate showed good homogenous dispersion, binding ability, and interfaces, as determined from FTIR, FESEM, and EDS analyses. The UV-DR analysis showed that all photocatalyst samples have lowest band gap of under $3.0 \mathrm{eV}$. The results indicated that 8-layer photocatalysts resulted in the optimal adsorption-photodegradation $\quad \mathrm{Cs}_{-}-\mathrm{TiO}_{2(\mathrm{SY})} /$ glass substrate, with the adsorption-photodegradation of $70 \%$ and adsorption of $50 \%$ of the MO solution.
Acknowledgments This work is financially supported by Fundamental Research Grant Scheme (FRGS: FP049-2013B) by University of Malaya and Ministry of High Education (MOE), Malaysia.

\section{References}

Ali I (2010) The quest for active carbon adsorbent substitutes: inexpensive adsorbents for toxic metal ions removal from wastewater. Sep Purif Rev 39(3-4):95-171

Ali I (2012) New generation adsorbents for water treatment. Chem Rev 112(10):5073-5091

Ali I (2014) Water treatment by adsorption columns: evaluation at ground level. Sep Purif Rev 43(3):175-205

Ali I, Asim M, Khan TA (2012) Low cost adsorbents for the removal of organic pollutants from wastewater. J Environ Manag 113:170-183

Bagheri S, Mohd Hir ZA, Termeh Yousefi A, Abd Hamid SB (2015) Photocatalytic performance of activated carbon-supported mesoporous titanium dioxide. Desalination Water Treat 1-7. doi:10. 1080/19443994.2015.1038593

Dutta PK, Dutta J, Tripathi VS (2004) Chitin and chitosan: chemistry, properties and applications. J Sci Ind Res 63(1):20-31

Fajriati I, Mudasir M, Wahyuni ET (2014) Photocatalytic decolorization study of methyl orange by $\mathrm{TiO}_{2}$-chitosan nanocomposites. Indones J Chem 14(3):209-218

Fujishima A (1972) Electrochemical photolysis of water at a semiconductor electrode. Nature 238:37-38

Gupta VK, Agarwal S, Saleh TA (2011a) Chromium removal by combining the magnetic properties of iron oxide with adsorption properties of carbon nanotubes. Water Res 45(6):2207-2212

Gupta VK, Agarwal S, Saleh TA (2011b) Synthesis and characterization of alumina-coated carbon nanotubes and their application for lead removal. J Hazard Mater 185(1):17-23

Gupta VK, Jain R, Mittal A, Saleh TA, Nayak A, Agarwal S, Sikarwar S (2012) Photo-catalytic degradation of toxic dye amaranth on $\mathrm{TiO}_{2} / \mathrm{UV}$ in aqueous suspensions. Mater Sci Eng C Mater Biol Appl 32(1):12-17

Jawad AH, Nawi M (2012) Fabrication, optimization and application of an immobilized layer-by-layer $\mathrm{TiO}_{2} /$ chitosan system for the removal of phenol and its intermediates under $45-\mathrm{W}$ fluorescent lamp. React Kinet Mech Catal 106(1):49-65

Kavitha K, Sutha S, Prabhu M, Rajendran V, Jayakumar T (2013) In situ synthesized novel biocompatible titania-chitosan nanocomposites with high surface area and antibacterial activity. Carbohydr Polym 93(2):731-739

Kijima T (2010) Inorganic and metallic nanotubular materials: recent technologies and applications, vol 117. Springer, Berlin

Kim TY, Lee Y-H, Park K-H, Kim SJ, Cho SY (2005) A study of photocatalysis of $\mathrm{TiO}_{2}$ coated onto chitosan beads and activated carbon. Res Chem Intermed 31(4):343-358

Kyzas GZ, Bikiaris DN (2015) Recent modifications of chitosan for adsorption applications: a critical and systematic review. Mar Drugs 13(1):312-337

Liu H, Ramnarayanan R, Logan BE (2004) Production of electricity during wastewater treatment using a single chamber microbial fuel cell. Environ Sci Technol 38(7):2281-2285

Nandini R, Vishalakshi B (2012) A study of interaction of methyl orange with some polycations. J Chem 9(1):1-14

Pereira L, Alves M (2012) Dyes-environmental impact and remediation. In: Environmental protection strategies for sustainable development. Springer, pp 111-162

Qian T, Su H, Tan T (2011) The bactericidal and mildew-proof activity of a $\mathrm{TiO}_{2}$-chitosan composite. J Photochem Photobiol A 218(1):130-136 
Saleh TA, Gupta VK (2012a) Photo-catalyzed degradation of hazardous dye methyl orange by use of a composite catalyst consisting of multi-walled carbon nanotubes and titanium dioxide. J Colloid Interface Sci 371(1):101-106

Saleh TA, Gupta VK (2012b) Synthesis and characterization of alumina nano-particles polyamide membrane with enhanced flux rejection performance. Sep Purif Technol 89:245-251

Saleh TA, Gondal MA, Drmosh QA (2010) Preparation of a MWCNT/ZnO nanocomposite and its photocatalytic activity for the removal of cyanide from water using a laser. Nanotechnology 21(49):495705

Saleh TA, Agarwal S, Gupta VK (2011) Synthesis of MWCNT/MnO and their application for simultaneous oxidation of arsenite and sorption of arsenate. Appl Catal B 106(1):46-53

Wongkupasert S (2008) The effect of salt form and molecular weight of chitosan for efficiency on siRNA delivery into cell. Silpakorn University, Bangkok
Yao K, Li J, Yao F, Yin Y (2011) Chitosan-based hydrogels: functions and applications. CRC Press, Boca Raton

Yu X, Lu Z, Wu D, Yu P, He M, Chen T et al (2014) Heteropolyacidchitosan/ $/ \mathrm{TiO}_{2}$ composites for the degradation of tetracycline hydrochloride solution. React Kinet Mech Catal 111(1):347-360

Zainal Z, Hui LK, Hussein MZ, Abdullah AH, Hamadneh IM (2009) Characterization of $\mathrm{TiO}_{2}$-chitosan/glass photocatalyst for the removal of a monoazo dye via photodegradation-adsorption process. J Hazard Mater 164(1):138-145

Zhang X, Zhao X, Su H (2011) Degradation characteristic of $\mathrm{TiO}_{2}-$ chitosan adsorbent on rhodamine $\mathrm{B}$ and purification of industrial wastewater. Korean J Chem Eng 28(5):1241-1246

Zhu H, Jiang R, Fu Y, Guan Y, Yao J, Xiao L, Zeng G (2012) Effective photocatalytic decolorization of methyl orange utilizing $\mathrm{TiO}_{2} / \mathrm{ZnO} /$ chitosan nanocomposite films under simulated solar irradiation. Desalination 286:41-48 